Gut, 1987, 28, S1, 63-69

\title{
Pancreatic growth: interaction of exogenous cholecystokinin, a protease inhibitor, and a cholecystokinin receptor antagonist in mice
}

\author{
C NIEDERAU, R A LIDDLE, J A WILLIAMS AND J H GRENDELL
}

From the Department of Medicine, University of Düsseldorf, FR Germany, Departments of Medicine and Physiology, University of California, San Francisco, Ca, and Cell Biology Research Laboratories, Mount Zion Hospital and Medical Center, San Francisco, Ca, USA

SUMMARY The effects on pancreatic growth and plasma CCK concentration of chronic feeding of camostate $(400 \mathrm{mg} / \mathrm{kg}$ day for 10 days), a potent inhibitor of serine proteases including trypsin, were assessed in the mouse. For comparison, the trophic effects of chronic exogenous administration of CCK octapeptide (sc injection of $1 \mu \mathrm{g} / \mathrm{kg}$ day every eight hours for 10 days) were also studied. In addition, the effects of a proglumide-analogue CCK-receptor antagonist (CR1409) on the stimulatory actions of camostate feeding and chronic administration of exogenous CCK were studied. The effects of the combination of chronic camostate feeding and sc injections of CCK, the effects of acute camostate feeding, and the effects of the CCK-receptor antagonist given without camostate or CCK were also studied. The results show that chronic camostate feeding markedly increased CCK plasma concentrations eight-fold over control values, and that acute camostate feeding increased plasma CCK concentration to four fold of control values. Correspondingly, chronic camostate feeding markedly increased pancreatic weight, protein and DNA content. Exogenous CCK-8 also had qualitatively similar, but quantitatively less potent stimulatory effects. The combination of camostate and CCK-8 resulted in an additive stimulatory effect. The trophic actions of exogenous and endogenous CCK grossly increased chymotrypsinogen content, but left amylase content unaffected. The CCK-receptor antagonist CR 1409 completely abolished the trophic effects of exogenous CCK and greatly inhibited the effects of chronic camostate feeding. The CCK antagonist decreased pancreatic weight, DNA and protein content compared to control values when given without any CCK or camostate. We conclude that the protease inhibitor camostate is a very strong release effector of $\mathrm{CCK}$ and exerts a powerful trophic effect on mouse pancreas which is probably mediated by CCK. Furthermore, physiological increases of CCK during feeding of regular chow appear to exert trophic effects on the exocrine pancreas.

It is well established that exogenous cholecystokinin and cholecystokinin analogues, like caerulein, stimulate pancreatic growth in the experimental animal. ${ }^{1-2}$ It is also well known that feeding of trypsin inhibitors markedly stimulates pancreatic growth. ${ }^{3-4}$ It has been shown recently, that pancreaticobiliary diversion also stimulates pancreatic growth. ${ }^{5-6}$ Both feeding of trypsin inhibitors and pancreaticobiliary diversion may stimulate pancreatic growth by the same mechanism of decreasing intraduodenal activity of pro-

Address for correspondence : Dr Claus Niederau, Medizinische Klinik, Abteilung für Gastroenterologie, Universität Düsseldorf, Moorenstr 5, 4000 Düsseldorf, FR Germany teases. The inhibition of intraduodenal proteolytic enzymes by potent protease inhibitors, such as camostate, ${ }^{7}$ or their diversion from the duodenum ${ }^{6}$ is thought to cause an increase in plasma CCK concentration which is suggested to mediate pancreatic growth under these conditions. ${ }^{5}$ It has, however, been speculated that other hormones like enteroglucagon may contribute to pancreatic growth after pancreaticobiliary diversion. ${ }^{8}$ Recent studies have tried to establish the hormone responsible for pancreatic growth after pancreaticobiliary diversion or feeding of a protease inhibitor by administration of proglumide, a specific CCK-inhibitor. ${ }^{6-9}$ The results 
showed that proglumide significantly inhibited pancreatic growth after pancreatico-biliary diversion and camostate feeding. ${ }^{6}$ Proglumide also inhibited pancreatic growth because of exogenous administration of CCK. ${ }^{10}$ In the previous studies, however, proglumide could only partly block pancreatic growth because of these stimuli. Furthermore, proglumide itself appeared to exert a trophic effect which was interpreted as a partial agonist activity of the CCK antagonist given in very high doses in these studies. ${ }^{9-10}$ The present study was designed to further examine the hypothesis that CCK plays a central role in regulation of pancreatic growth. Pancreatic growth was monitored both after exogenous CCK -8 and after chronic feeding of camostate which is a potent inhibitor of serine proteases. ${ }^{7}$ These same conditions were also studied with administration of a recently described CCK-receptor antagonist CR1409 which is at least 1000 more potent than proglumide in vitro. ${ }^{11-12}$ Further experiments studied pancreatic growth after the combination of exogenous CCK and feeding of camostate and with administration of the CCK antagonist alone. In addition, plasma CCK concentrations were monitored under these experimental conditions.

\section{Methods}

MATERIALS

Camostate (FOY 305) was a generous gift from Sanol-Schwarz (Monheim, FR Germany). The CCKreceptor antagonist CR1409 D,L-4-(3,4-dichlorobenzoyl-amino)-5-(di-n-pentyl-amino)-5-oxopentaoic acid was a generous gift from Prof I Setnikar (Rotta Laboratories, Milan, Italy). Cholecystokinin octapeptide (CCK-8) was purchased from Squibb (Princeton, NJ). The fluorescent compound Hoechst 33258 used for the DNA assay was purchased from American Hoechst. All other chemicals were purchased from Sigma Chemicals (St Louis, MO).

\section{EXPERIMENTAL PROTOCOL}

Male Swiss Webster mice (Simonson Laboratories, Gilroy, CA), weighing $20-25 \mathrm{~g}$, were used in this study. All mice were fed regular laboratory chow ad libitum before the experiments and had unlimited access to water throughout the experiments.

In the first set of experiments, mice were randomly assigned to seven different experimental groups with 24 mice being assigned to each group. The control group was fed regular chow throughout the experiments. In three groups camostate was mixed with regular chow $(2 \mathrm{~g} / \mathrm{kg})$. This mixture was fed ad libitum to mice for 10 days to achieve a daily dose of approximately $400 \mathrm{mg} / \mathrm{kg}$ camostate (ranging from 380 to $430 \mathrm{mg} / \mathrm{kg}$ for the different experimental groups). One of the camostate fed groups received no additional treatment; the second of the camostate fed groups received sc injections of $10 \mathrm{mg} / \mathrm{kg}$ CR 1409 every eight hours for the 10 days; the third of the camostate fed groups received sc injections of $1 \mu \mathrm{g} /$ $\mathrm{kg} \mathrm{CCK}-8$ every eight hours for the 10 days. Mice in additional three experimental groups were fed regular chow. The first one of these groups received sc injections of $10 \mathrm{mg} / \mathrm{kg} \mathrm{CR} 1409$ every eight hours for 10 days; the second one received sc injections of $1 \mu \mathrm{g} /$ kg CCK-8 every eight hours for 10 days; and the third one received both $10 \mathrm{mg} / \mathrm{kg} \mathrm{CR} 1409$ and $1 \mu \mathrm{g} / \mathrm{kg}$ CCK-8 every eight hours for 10 days with the antagonist being given 15 minutes before CCK-8. Mice were killed after 10 days with the corresponding diets fed ad libitum and eight hours after the last injection of CCK or antagonist. In the second set of experiments three groups of 24 mice each were fasted for 16 hours before the experiments (all mice in these groups had been fed regular chow before fasting). The first one of these groups served as a control, the second one was acutely fed $400 \mathrm{mg} / \mathrm{kg}$ camostate through an orogastric tube, and the third one received instead of camostate the same volume of $0.9 \%$ saline through the tube as a further control. Mice in these groups were killed 30 minutes after administration of camostate or saline.

\section{BIOCHEMICAL DETERMINATIONS IN}

PANCREATIC TISSUE

Mice were killed by decapitation and the pancreas was quickly removed and weighed in all animals. The pancreas of every second mouse (12 mice per group) was then suspended in $3 \mathrm{ml}$ ice cold $5 \mathrm{mM} \mathrm{MgCl}_{2}$ solution containing $0.1 \%$ Triton X-100, homogenised using an electrically driven Teflon glass pestle at high speed, and sonicated for 20 seconds. Protein concentration was determined using the Lowry method with bovine serum albumin as a standard. ${ }^{13}$ DNA concentration was determined with the fluorescent Hoechst reagent $33258 .{ }^{14}$ Chymotrypsinogen cencentration was determined after activation with trypsin. ${ }^{15-16}$ Amylase concentration was determined using the Phadebas amylase assay (Pharmacia, Piscataway, NJ).

\section{MEASUREMENT OF PLASMA CCK}

Trunk blood from decapitated mice was collected into iced heparinised tubes. The amount of blood obtained from each mouse ranged from $0.4-0.6 \mathrm{ml}$; therefore blood samples from four mice of the same experimental group were pooled for each single CCK determination. Blood was then immediately centrifuged at $4^{\circ} \mathrm{C}$ for recovery of plasma. Plasma CCK was measured using a bioassay as previously described for rat and human plasma. ${ }^{17-18}$ Briefly, CCK was 
extracted from mouse plasma by adsorption on octadecylsilylsilica (Sep-Pak) cartridges (Waters Assoc, Milford, MA) and eluted with $1 \mathrm{ml} 80 \%$ ethanol and $0.2 \%$ trifluoroacetic acid $(4: 1, v / v)$ into incubation vials and dried under nitrogen. CCK in these extracts was quantified by its ability to stimulate amylase release from isolated rat pancreatic acini, prepared by collagenase digestion of rat pancreas. Values were compared with a standard curve of CCK-8 and results were expressed as CCK-8 equivalents (pM). The assay was sensitive to CCK levels as low as $1 \mathrm{pM}$ and with the ability to concentrate plasma up to four fold (by adsorbing $4 \mathrm{ml}$ plasma onto a single Sep-Pak and eluting it in $1 \mathrm{ml}$ ) plasma CCK levels as low as $0.25 \mathrm{pM}$ could be detected. In a previous report ${ }^{19}$ we have verified that the amylase stimulatory properties of mouse plasma extracts on isolated pancreatic acini were indeed due to CCK, as previously shown for rat and human plasma extracts. ${ }^{17-18}$

\section{STATISTICAL ANALYSIS}

Means of the biochemical determination in pancreatic tissue and plasma CCK concentrations under the different experimental conditions were compared with the corresponding control values of chow fed mice by analysis of variance using Duncan's method..$^{20-21}$ Mean plasma CCK concentrations after acute feeding of camostate or saline were compared with mean CCK concentrations in fasted mice by a two-tailed Student's $t$ test for unpaired value.

\section{Results}

\section{EFFECTS ON PANCREATIC TISSUE}

Chronic feeding of camostate markedly stimulated pancreatic weight, protein content and DNA content (Fig. 1). Chymotrypsinogen content was almost doubled by camostate feeding, whereas amylase content remained unchanged (Fig. 2). Injections of CCK-8 also significantly increased pancreatic weight, protein content, DNA content (Fig. 1) as well as chymotrypsinogen content, but left amylase content unaffected (Fig. 2), and thus had qualitatively similar, but quantitatively smaller effects compared to camostate feeding. The combined administration of CCK-8 and camostate was more effective than either substance alone in increasing pancreatic weight, protein content, DNA content (Fig. 1), as well as chymotrypsinogen content, but still left amylase content unchanged (Fig. 2). The effects of camostate and CCK-8 were approximately additive. When the CCK-antagonist CR1409 was given together with CCK-8 (or more precisely shortly before each injection of CCK-8) pancreatic weight, protein and DNA content, as well as chymotrypsinogen and amylase
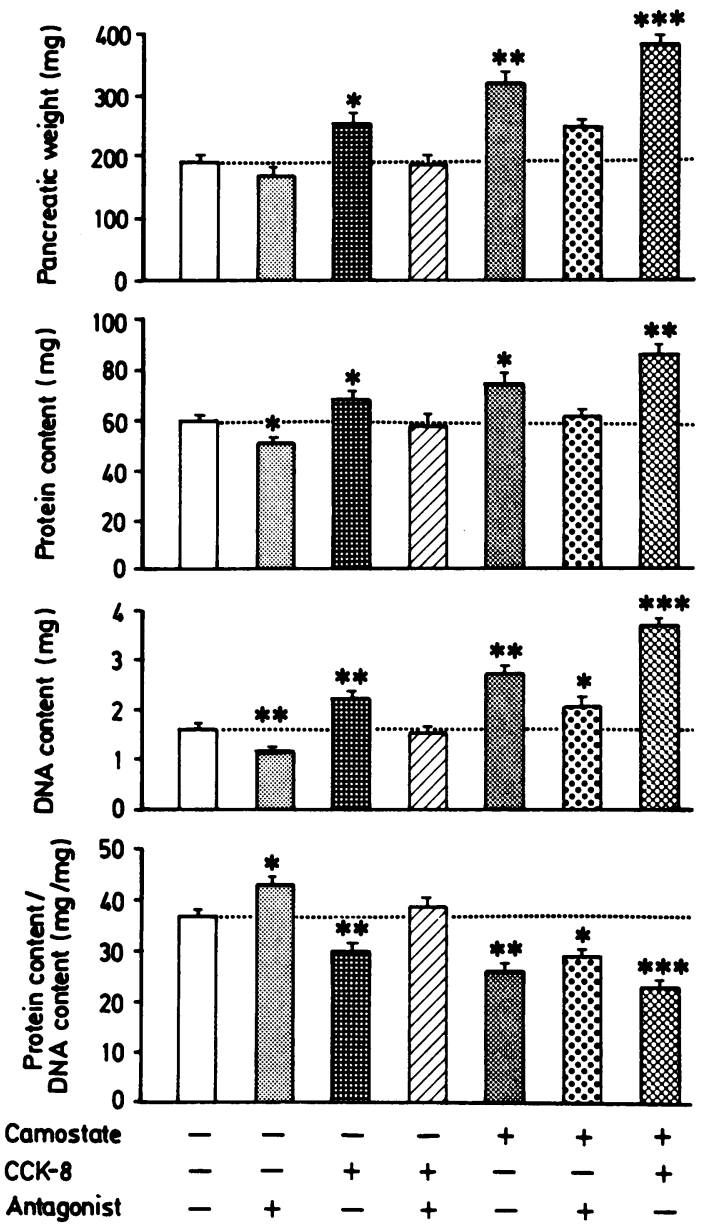

Fig. 1 Mean $\pm S E$ of pancreatic weight $(n=24)$, protein content $(n=12), D N A$ content $(n=12)$, and ratio of protein content/DNA content $(n=12)$. The different experimental conditions are as indicated: 'Camostate' was mixed with regular chow and fed to achieve a daily dose of $400 \mathrm{mg} / \mathrm{kg}$ for 10 days; no camostate (-) indicates that regular chow was fed ad libitum; 'CCK-8' was given as sc injections of $1 \mu \mathrm{g} / \mathrm{kg}$ every 8 hours for 10 days; the CCKreceptor 'antagonist' was given as sc injections of $10 \mathrm{mg} / \mathrm{kg}$ every eight hours. In mice, which received CCK-8 injections, the antagonist was given $15 \mathrm{~min}$ before the injection of $C C K-8$. The means of the data for the various conditions in the experimental groups were statistically compared with the corresponding mean data of the group which received no camostate, CCK-8, or antagonist by analysis of variance using Duncan's methods (26-27). Levels of significance are as indicated: $* P \leqslant 0.05,{ }^{* *} P \leqslant 0.01,{ }^{* * *} P \leqslant 0.001$. 'NS' indicates $P>0.05$.

content remained unchanged compared to the chow fed controls (Figs 1, 2), and thus the CCK antagonist completely blocked all stimulatory effects of exogenous CCK-8. When the CCK antagonist was given 

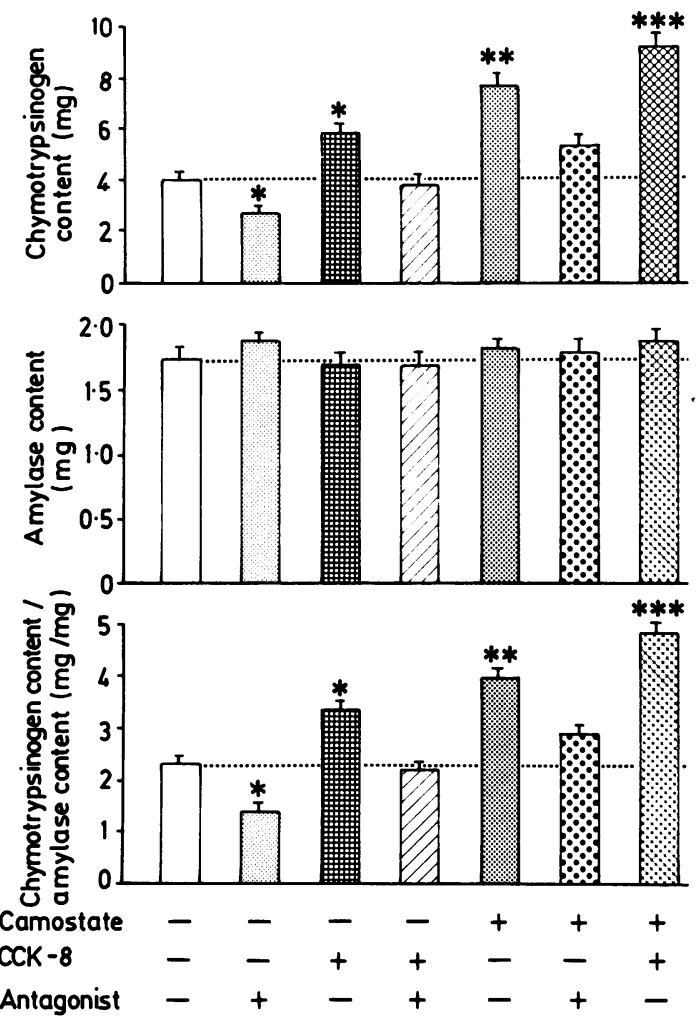

Fig. 2 Mean $\pm S E(n=12)$ of pancreatic content of chymotrypsinogen, pancreatic content of amylase, and of the ratio of chymotrypsinogen content/amylase content. For different experimental conditions and statistical analysis see legend to Figure 1.

in addition to camostate feeding, pancreatic weight, protein content, and chymotrypsinogen and amylase content showed no statistically significant increase compared with the chow fed control (increase of weight and chymotrypsinogen was on the borderline of statistical significance) (Figs 1, 2). Although DNA content significantly increased in camostate fed mice which received the CCK antagonist, the increase in DNA was much less than observed in camostate-fed mice which did not receive the CCK antagonist (Fig. 1).

Chow fed mice which received chronic injection of the CCK antagonist without CCK-8 or camostate showed a significant decrease in pancreatic content of protein, DNA, and chymotrypsinogen (Figs 1, 2). Pancreatic weight also decreased, but this decrease did not reach statistical significance (Fig. 1). Amylase content again remained unchanged (Fig. 2).

Chronic camostate feeding and CCK-8 injections, as well as the combination of both treatments decreased the ratio of protein/DNA in pancreatic tissue (the decrease of protein/DNA ratio in mice receiving injections of CCK-8 was on the borderline of statistical significance) (Fig. 1). The decrease of protein/DNA ratio was reversed toward the control ratio for chow fed mice when the CCK antagonist was given in addition to camostate feeding or CCK-8 injections (Fig. 1). Thus, both exogenous CCK-8 and camostate feeding appeared to result primarily in hyperplasia of the pancreas rather than hypertrophy.

Chronic camostate feeding and injections of CCK-8, as well as the combination of both treatments significantly increased the ratio of chymotrypsinogen/ amylase in the pancreas (Fig. 2). This increase was reversed to values which were not significantly different from values in chow fed controls by additional administration of the CCK antagonist (Fig. 2). On the other hand, administration of the antagonist without camostate or CCK-8 significantly decreased the ratio of chymotrypsinogen/amylase (Fig. 2).

\section{EFFECTS ON PLASMA CCK CONCENTRATION}

Chronic feeding of camostate significantly increased plasma CCK concentrations to almost eight times the control values for chow fed mice (Fig. 3). Chronic injections of CCK-8 in addition to camostate feeding also resulted in an approximately 8-fold increase in plasma CCK (Fig. 3). These plasma CCK levels are an approximately 40 -fold increase above levels in fasted mice (compare corresponding data given in Fig. 3, a,b). Previous experiments (data not given in detail) have shown that a single sc injection of $2 \mu \mathrm{g} /$ $\mathrm{kg}$ b.w. CCK-8 results in a plasma CCK concentration of about $40-50 \mathrm{pM}$ measured $30 \mathrm{~min}$ after the injection. After sc injection of CCK, however, plasma CCK levels rapidly decrease toward previous control values. Correspondingly, plasma CCK levels measured eight hours after the last injections of CCK-8 were indistinguishable from mice which received no CCK-8 (Fig. 3). In chow fed mice which received only the CCK antagonist, plasma CCK concentrations eight hours after the last injection of the antagonists remained unchanged compared to chow fed mice which did not receive the antagonist (Fig. 3). Camostate fed mice which received the antagonist did not show a significant increase in plasma CCK concentrations (although the actual mean of CCK concentration was twice as high as the chow fed control this increase did not reach statistical significance) (Fig. 3). Thus, the CCK antagonist appeared to inhibit the increase in plasma CCK due to camostate feeding.

Acute feeding of camostate also significantly increased plasma CCK concentrations $\mathbf{3 0}$ minutes after administration of $400 \mathrm{mg} / \mathrm{kg}$ camostate through an orogastric tube to more than four-fold the values of 


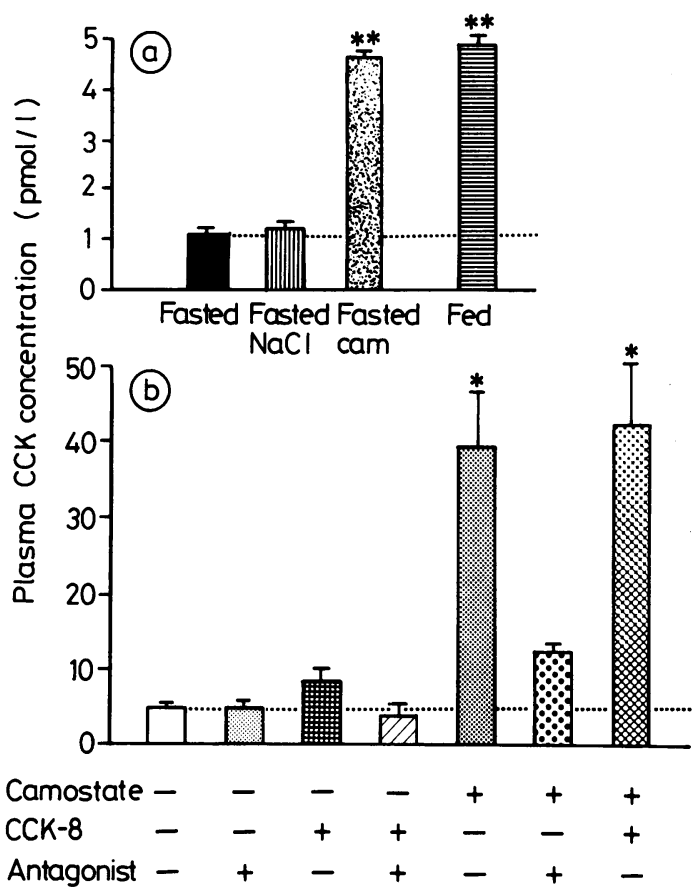

Fig. 3 Mean $\pm S E$ of plasma CCK concentration of a total of six CCK determinations for each different experimental group; blood from four mice of the same experimental group were pooled for a single CCK determination (see Methods) yielding a total of six CCK determinations for each different experimental group of 24 mice. For the experimental conditions indicated in the lower part of the figure (b) see legend to Figure 1. The experimental conditions given in the upper part of the Figure (a) are as indicated: 'fed' indicates experiments with mice which had been fed regular chow ad libitum, the same bar is also shown as the most left bar in the lower part of the figure; 'fasted' indicates experiments with mice which had been fasted for 16 hours prior to the experiments and had been fed regular chow prior to fasting; 'fasted cam' indicates experiments in which a single bolus administration of 400 $\mathrm{mg} / \mathrm{kg}$ camostate was given through an orogastric tube. 'fasted $\mathrm{NaCl}$ ' indicates experiments in which, instead of camostate, the same volume of $0.9 \% \mathrm{NaCl}$ was administered through an orogastric tube. Mice in the 'fasted cam' and 'fasted $\mathrm{NaCl}$ ' groups were sacrificed 30 minutes after administration of camostate or $\mathrm{NaCl}$. For statistical analysis see legend to Figure 1.

fasted mice or values in mice which received, instead of camostate, the same volume of saline through the orogastric tube (Fig. 3).

\section{Discussion}

The results show that feeding of the protease inhibitor camostate for 10 days exerts a marked stimulatory effect on the growth of the mouse pancreas. The present results also strongly indicate that an increase in plasma CCK concentration is responsible for the stimulatory effect of camostate on pancreatic growth. Chronic camostate feeding did not only markedly increase plasma CCK concentration to eight times of control values of chow fed mice, but simultaneous administration of a CCK inhibitor greatly reduced the stimulatory effect of camostate. It is also remarkable that plasma CCK levels in fasted mice increased four-fold 30 minutes after a single dose of camostate given by an orogastric tube. This shows that the 'feedback' effect causing a CCK release in response to inhibition of intraduodenal proteases, previously described in the rat, ${ }^{5-7}$ exists in the mouse, too.

Exogenous CCK-8 had qualitatively similar but quantitatively smaller stimulatory effects on pancreatic growth compared with camostate feeding. The relatively small effect of CCK-8 compared to camostate feeding is, however, to be expected in view of the CCK plasma concentration measured under these conditions. Other experiments had shown that sc injections of $2 \mu \mathrm{g} / \mathrm{kg} \mathrm{CCK}-8$ resulted in plasma CCK concentrations 30 minutes after the injection which were in the range of those observed in the camostate fed mice. ${ }^{19}$ The plasma CCK concentration after a sc injection of CCK-8, however, peaks after approximately 30 minutes and then rapidly decreases toward previous control values. ${ }^{19}$ Thus, the plasma CCK concentration in camostate-fed mice integrated over the entire study period of 10 days was probably substantially higher than in chow fed mice which received sc injections of CCK-8. Injections of the CCK antagonist in addition to (or more precisely shortly before each) injection of CCK-8 completely blocked all stimulatory effects of CCK-8 on pancreatic growth. This blockade of CCK's action on pancreatic growth shows that the recently described proglumide analogue CR1409, characterised as a CCK-receptor antagonist by in vitro studies in membranes and cells, also acts as an antagonist of the action of CCK in vivo in the whole animal. Furthermore, CR1409 is effective in vivo at a much lower dose $(10 \mathrm{mg} / \mathrm{kg})$ than is proglumide $(100$ $1000 \mathrm{mg} / \mathrm{kg}){ }^{69-10}$ In view of the very rapid, longlasting and marked stimulatory effects of camostate on plasma CCK concentrations, it is not surprising that the three daily sc injections of the CCK antagonist were not sufficient to completely block camostate's and thus probably CCK's stimulatory actions on pancreatic growth. On the contrary, the observation that the CCK antagonist injected only every eight hours could greatly block the effect of camostate, and thus probably the effect of CCK, indicates the powerful potential of the recently described CCK-receptor antagonist. 
In two recent reports about proglumide's inhibitory action on CCK-stimulated pancreatic growth, proglumide was reported to have a partial agonist activity when given without any exogenous CCK or substances which may release endogenous CCK such as trypsin inhibitor. ${ }^{9-10}$ This is not true for the CCK antagonist used here. The new antagonist CR1409, given without exogenous CCK or substances which may release endogenous CCK, did not show any stimulation of pancreatic growth and, thus, no partial agonist activity. On the contrary, when the CCK antagonist was given without exogenous CCK or camostate it exerted significant antitrophic effects on the pancreas. This is direct evidence that the physiological increases of CCK in response to feeding of regular chow diet have a significant trophic effects on the exocrine pancreas. This is in accordance with the experimental and clinical observations that long term parenteral nutrition results in a reversible pancreatic atrophy. ${ }^{22-23}$ The present results suggest that lack of the physiological increases in CCK which occur in response to oral food may be responsible for this atrophy.

Surprisingly, the CCK antagonist CR1409 inhibited not only the effects of CCK, which was found markedly increased during camostate feeding, but also decreased the plasma CCK concentration seen in response to camostate feeding. This may, at least in part, be because of the effect of residual CCK antagonist in plasma samples, obtained eight hours after the last injection, interfering with the CCK bioassay and producing artifactually decreased values.

Most previous studies done in the rat showed that CCK and CCK analogues, like caerulein, increase both the absolute DNA content of the pancreas and the ratio of protein/DNA, and thus exert both hypertrophic and hyperplastic effects on the pancreas. $^{1-2}$ In the present experiments in the mouse camostate feeding and exogenous CCK appeared to induce almost exclusively hyperplasia. The lack of hypertrophy may, however, be because the mice were kept on the diets ad lib. Thus, in particular in camostate fed mice, there was still an ongoing stimulation of exocrine secretion resulting in depletion of cellular protein at the time of death. It might be that fasting the mice before death would result in a greater increase in protein content and show hypertrophy. Similar to previous reports in the rat, ${ }^{924}$ both exogenous CCK and even to a greater degree feeding of the protease inhibitor markedly increased the content of the proteolytic enzyme chymotrypsinogen, but left that of the starch splitting enzyme amylase completely unaffected.

In summary, the present results give convincing evidence that CCK plays an important and probably central role in mediating pancreatic growth under physiological conditions. The new CCK-antagonist CR1409 appears to be a powerful tool to further investigate other physiological actions of CCK.

Dr Niederau was supported by the Deutsche Forschungsgemeinschaft (Ni 224/2-1). The authors thank Dr B Göke for helpful discussions.

\section{References}

1 Dembinski AR, Johnson LR. Stimulation of pancreatic growth by secretin, cerulein, and pentagastrin. Endocrinology 1978; 106: 232-328.

2 Fölsch UR, Winckler K, Wormsley KG. Influence of repeated administration of cholecystokinin and secretin on the pancreas of the rat. Scand J Gastroenterol 1978; 13: 663-71.

3 Chernik SS, Lepowski S, Chaikoff IL. A dietary factor regulating the enzyme content of the pancreas: changes in size and proteolytic activity of chick pancreas by the ingestion of raw soy bean meal. Am J Physiol 1948; 155: 33-41.

4 Fölsch UR, Winckler K, Wormsley KG. Effect of soybean diet on enzyme content and ultrastructure of the rat exocrine pancreas. Digestion 1974; 11: 161-71.

5 Green GM, Lyman RL. Feedback regulation of pancreatic enzyme secretion as a mechanism for trypsin inhibitor-induced hypersecretion in the rat. Proc Soc Exp Biol Med 1972; 140: 6-12.

6 Miazza BM, Turberg Y, Guillaume P, Hahnen W, Chayvialle JA, Loizeau. Mechanism of pancreatic growth induced by pancreatico-biliary diversion in the rat. Digestion 1985; 20: 75-83.

7 Yonezawa $H$. Discrepancy between the potency of various trypsin inhibitors to inhibit trypsin activity and the potency to release biologically active cholecystokinin-pancreozymin. Jpn J Physiol 1984; 34: 849-56.

8 Dowling RH. Small bowel adaption and its regulation. Scand J Gastroenterol 1982; 74: 53-74.

9 Göke B, Printz H, Richter G, Adler G, Arnold R. Beeinflussung der Pankreas-hypertrophie infolge Camostategabe durch Injektion des CCK-Antagonisten Proglumid. Klin Wochenschr 1986; 64: A54.

10 Yamaguchi T, Tabat K, Johnson LR. Effect of proglumide on rat pancreatic growth. Am J Physiol 1985 (Gastrointest Liver Physiol 12); 249: G294-298.

11 Makovec F, Chinte R, Bani M, Pacini MR, Setnikar I, Rovati LA. New glutaramic acid derivatives with potent competitive and specific cholecystokinin-antagonistic activity. Arzneim Forsch 1985; 35: 1048-51.

12 Niederau C, Niederau M, Williams JA, Grendell JH. New proglumide-analogue CCK receptor antagonists: very potent and selective for peripheral tissues. $\mathrm{Am} \mathrm{J}$ Physiol 1986; 251: G856-G860.

13 Lowry OH, Rosebrough NJ, Farr AL, Randall RJ. Protein measurements with Folin phenol reagent. J Biol Chem 1951; 193: 265-75.

14 Labarca C, Paigen K. A simple, rapid, and sensitive DNA assay procedure. Anal Biochem 1980; 102: 34452. 
15 Hummel BCW. A modified spectrophotometric determination of chymotrypsin, trypsin, and thrombin. Can J Biochem Physiol 1959; 37: 1393-9.

16 Glazer G, Steer ML. Requirements for activation of trypsinogen and chymotrypsinogen in rabbit pancreatic juice. Anal Biochem 1977; 77: 130-40.

17 Liddle RA, Goldfine ID, Williams JA. Bioassay of plasma cholecystokinin in rats: effects of food, trypsin inhibitor, and alcohol. Gastroenterology 1984: 87: 5429

18 Liddle RA, Goldfine ID, Rosen MS, Taplitz RA, Williams JA. Cholecystokinin bioactivity in human plasma: molecular forms, responses to feeding, and relationship to gallbladder contraction. $J$ Clin Invest 1985; 75: 1140-2.

19 Niederau C, Liddle RA, Ferrell LD, Grendell JH. Beneficial effects of CCK-receptor blockade and inhibition of proteolytic activity in experimental acute pancreatitis in mice: evidence for cholecystokinin as a major factor in the development of acute pancreatitis. $J$ Clin Invest. 1986 (in press).

20 Byrkit DR. Analysis of variance. In: Elements of statistics New York: Van Nostrand, 1980: 305-58.

21 Duncan DB. Multiple rank tests for correlated and heteroscedastic means. Biometrics 1957; 13: 164-76.

22 Johnson LR, Schanbacher LM, Dudrick SJ, Copeland EM. Effect of long-term parenteral feeding on pancreatic secretion and serum secretin. Am J Physiol 1977; 233: E524-E529.

23 Kotler DP, Levine GM. Reversible gastric and pancreatic hyposecretion after long-term parenteral nutrition. $N$ Engl J Med 1979; 300: 241-2.

24 Schick J, Kern H, Scheele G. Hormonal stimulation of the exocrine pancreas results in coordinate and anticoordinate regulation of protein synthesis. $J$ Cell Biol 1984; 99: 1569-74. 